O DEVER FUNDAMENTAL DE PRESERVAR A INCOLUMIDADE DAS PESSOAS (ART. 144, CRFB/88) E A ATUAÇÃO NA PREVENÇÃO DOS SUICÍDIOS: O CASO DA TERCEIRA PONTE - RODOSOL/ES

THE FUNDAMENTAL DUTY TO PRESERVE PEOPLE'S INCOLUITY (ARTICLE 144, CRFB / 88) AND THE ACTION IN THE PREVENTION OF SUICIDES: THE CASE OF THE THIRD BRIDGE - RODOSOL / ES

\title{
Adriano Sant'Ana Pedra ${ }^{1}$
}

Eduardo Bergamim Uliana²

\section{Resumo}

O presente artigo buscou analisar se a Rodosol, concessionária que administra a Ponte Deputado Darcy Castelo de Mendonça (Terceira Ponte), tem ou não o dever fundamental de preservar a incolumidade das pessoas (art. 144, da CRFB/88), atuando na prevenção dos suicídios que ocorrem no local. Além disso, analisou-se quem arcaria com os custos dessas medidas preventivas implementadas. O método empregado foi o estudo de caso, tendo em vista que os casos de suicídios que acontecem na Terceira Ponte/ES mostram-se como um fenômeno atual, inserido na realidade do Estado do Espírito Santo. Ao final, foi possível chegar à conclusão de que a concessionária Rodosol, uma pessoa jurídica, também possui o dever fundamental de preservar a incolumidade das pessoas, atuando na prevenção dos suicídios que ocorrem na Terceira Ponte, tendo como base dois direitos previstos na Constituição, quais sejam: o direito à vida e à segurança pública. Verificou-se, ainda, que o dever fundamental de preservar a incolumidade das pessoas é de responsabilidade de todos. Assim, com equidade, entendeu-se que o custo oriundo das medidas específicas adotadas para prevenir os suicídios que ocorrem na Terceira Ponte, deverá ser arcado por toda a sociedade, por meio da receita pública.

Palavras-chave: Suicídio. Ponte Deputado Darcy Castelo de Mendonça. Segurança Pública. Direitos e deveres fundamentais. Custos dos direitos.

\footnotetext{
${ }^{1}$ Doutor em Direito Constitucional (PUC/SP). Mestre em Direitos e Garantias Fundamentais (FDV). Professor do Programa de Pós-Graduação Stricto Sensu - Mestrado e Doutorado - em Direitos e Garantias Fundamentais da FDV. Membro do grupo de pesquisa "Estado, Democracia Constitucional e Direitos Fundamentais" (FDV). Procurador Federal.E-mail: adrianopedra@fdv.br

${ }^{2}$ Graduando em Direito pela Faculdade de Direito de Vitória/ES (FDV). E-mail: eduardobergamimuliana@gmail.com
} 


\section{Abstract}

The present article aimed to analyze whether or not Rodosol, a concessionaire that manages the Congressman Darcy Castelo de Mendonça Bridge (Third Bridge) has or does not have the fundamental duty of preserving the people's safety (article 144 of CRFB / 88), acting on the prevention of suicides that occur on the spot. In addition, it was analyzed who would bear the costs of these preventive measures implemented. The method employed was the case study, considering that the cases of suicides that occur on the Third Bridge/ES, are shown as a current phenomenon, inserted in the reality of the State of Espírito Santo. In the end, it was possible to conclude that the concessionaire Rodosol, a legal entity, also has the fundamental duty of preserving the safety of people, acting on preventing suicides that occur on the Third Bridge, based on two rights provided by the Constitution, which are: the right to life and public safety. It was also verified that the fundamental duty of preserving people's safety is a responsibility of all. Thus, with equity, it was understood that the costs of specific measures taken to prevent the suicides occurring in the Third Bridge should be borne by society as a whole, through public revenue.

Keywords: Suicide. Congressman Darcy Castelo de Mendonça Bridge. Public security. Fundamental rights and duties. Costs of rights.

INTRODUÇÃO

A Terceira Ponte, oficialmente conhecida como Ponte Deputado Darcy Castelo de Mendonça, é responsável por fazer a ligação entre as cidades de Vitória e Vila Velha, no Espírito Santo - Brasil. Além da bela vista, tal Ponte tem recebido destaque por um aspecto negativo, a saber: os repetidos casos de suicídio.

O próprio Ministério Público do Estado do Espírito Santo já chegou a questionar, em junho de 2014, as mortes ocorridas na Terceira Ponte, acionando a Rodosol - empresa que administra a Ponte -, para solicitar o número de suicídios cometidos no local. O pedido efetuado pelo MPES teve como fundamento o direito à vida, que é assegurado na Constituição da República Federativa do Brasil de 1988 (CRFB/88), sendo dever do Estado garanti-lo e dever do Ministério Público do Estado do Espírito Santo defender os direitos coletivos (VAREJÃO, 2014). 
Vale destacar que o Legislativo do Espírito Santo já se atentou para a causa, por meio do projeto de lei 35/2014, do Deputado Euclério Sampaio, que foi arquivado em decisão do plenário da Assembleia Legislativa, que acatou o parecer pela inconstitucionalidade do referido projeto (ESPÍRITO SANTO, 2014). Tal projeto de lei tornava obrigatório a colocação de grades ou telas de proteção em toda a extensão da Terceira Ponte, com altura mínima de 3 metros.

Sobre o suicídio, a Organização Mundial da Saúde já emitiu seu alerta: "[...] um maior número de pessoas comete suicídio anualmente do que as que morrem em todos os conflitos mundiais combinados". Estima-se que mais de um milhão de pessoas tenha cometido suicídio em 2000, o que coloca o suicídio entre as dez causas que mais provocam morte em diversos países do mundo. Ainda, no que tange às estatísticas, cumpre mencionar que as taxas de suicídio aumentaram aproximadamente em 60\% nos últimos 50 anos (OMS, 2006, p. 1-3).

Ao analisar o fenômeno no âmbito nacional, verifica-se que no Brasil 11 mil pessoas tiram a própria vida por ano, em média, sendo que o país registrou um aumento na taxa de mortalidade por suicídio. Em 2011, o número de óbitos por suicídio foi de 10.490, alcançando o patamar de 11.736 óbitos no ano de 2015. Vale mencionar ainda que entre 2011 e 2016 foram notificadas 176.226 lesões autoprovocadas, das quais 27,4\% (48.204) foram tentativas de suicídio (BRASIL, 2017).

No que tange ao Estado do Espírito Santo, em um estudo da série histórica de mortalidade por suicídio no Espírito Santo (de 1980 a 2006), constatou-se que, no período de estudo, aconteceram 2.604 mortes por suicídio. Além disso, concluiu-se que há uma tendência de crescimento das taxas de suicídio nas macrorregiões Metropolitana, Noroeste e Sul (MACENTE; ZANDONADE, 2011, p. 153-157), sendo que a Terceira Ponte está situada, justamente, na macrorregião Metropolitana.

Diante desse cenário, o presente artigo, desenvolvido a partir de pesquisas bibliográficas, buscou analisar se a Rodosol, empresa que administra a Terceira Ponte, tem ou não o dever fundamental de preservar a incolumidade física dos usuários, atuando na prevenção dos suicídios que ocorrem no local, como uma forma de assegurar o direito à segurança pública (art. 144, da CRFB/88) e o direito à vida (art. 5, da CRFB/88). Buscou-se, também, definir quem são os responsáveis por arcar com os custos das medidas preventivas adotadas pela Rodosol, a partir da responsabilidade de todos para com a incolumidade das pessoas.

Além disso, analisou-se dados sobre o número de suicídios que ocorreram na Terceira Ponte nos últimos anos, como uma forma de retratar a relevância da discussão sobre o tema. Tais dados foram obtidos a partir de estatísticas divulgadas pela própria Rodosol e pelo governo do Estado do Espírito Santo. 
Como a questão do suicídio é um problema de toda a sociedade, trabalhar no sentido de especificar quem são os responsáveis por atuar na sua prevenção, mostra-se como peça fundamental para se alcançar resultados positivos no combate dos suicídios e, consequentemente, na preservação de direitos fundamentais.

Ademais, verificar se uma pessoa jurídica também possui o dever fundamental de preservar a incolumidade das pessoas, atuando na prevenção dos suicídios, contribui para a academia no sentido de aplicar, ao caso concreto, a teoria geral dos direitos e deveres fundamentais.

No que tange à metodologia, será utilizado o método estudos de casos, que "[...] representam a estratégia preferida quando se colocam questões do tipo 'como' e 'por que', quando o pesquisador tem pouco controle sobre os eventos e quando o foco se encontra em fenômenos contemporâneos inseridos em algum contexto da vida real" (YIN, 2003, p. 19).

Diante disso, verifica-se que os repetidos casos de suicídios que ocorrem na Terceira Ponte/ES mostram-se como um fenômeno atual, inserido na realidade do Estado do Espírito Santo, sendo o estudo de caso o método adequado para o presente trabalho. Isso ocorre porque trata-se de uma situação única e contemporânea, sendo, dessa forma, necessário realizar uma investigação empírica, para analisar se a Rodosol, uma empresa concessionária de serviços públicos, possui ou não o dever fundamental de preservar a incolumidade das pessoas, atuando na prevenção dos suicídios que ocorrem na Terceira Ponte, como uma forma de garantir o direito à vida e à segurança pública dos usuários.

Visto isso, o presente estudo começa analisando o conceito de suicídio e as estatísticas dos suicídios na Terceira Ponte, para, posteriormente, analisar a teoria geral dos direitos e deveres fundamentais, destacando-se o direito à segurança pública, no que se refere à preservação da incolumidade das pessoas, e o direito à vida. Logo em seguida, aborda-se o dever fundamental da Rodosol de preservar a incolumidade física dos usuários da Terceira Ponte, atuando na prevenção dos suicídios por meio de medidas específicas, dentro do contexto de um contrato de concessão, para ao final, definir os responsáveis por arcar com os custos das medidas preventivas adotadas.

\section{O SUICÍDIO}

Émile Durkheim, sociólogo francês, na introdução do seu livro "O suicídio" [1897], alerta para a necessidade de se conceituar o objeto da pesquisa, isto é, o termo suicídio, para que se possa realizar uma análise dos fatos de forma homogênea e específica. Deste modo, não é possível fazer 
uma análise rasa, pautada no sentido vulgar do que seria suicídio, uma vez que para comparar os diferentes tipos de morte, é preciso que haja fundamentos objetivos (DURKHEIM, 2000, p. 10).

A partir disso, ele propõe uma definição científica do suicídio, que é "[...] toda morte que resulta mediata ou imediatamente de um ato positivo ou negativo, realizado pela própria vítima e que ela sabia que produziria esse resultado (DURKHEIM, 2000, p. 14).

Ciente de tal definição cientifica, insta esclarecer que Durkheim revelou que o ato suicida não é um ato isolado, visto que o mesmo é influenciado por questões externas, como a anomia, que é um "sentimento de falta de propósito, medo, desespero" (GIDDENS, 2012, p. 26).

Durkheim busca ressaltar que apesar de parecer tão íntimo, o suicídio recebe influências da sociedade, visto que o indivíduo age de acordo com padrões sociais. Assim, tal autor fez uma análise sociológica do suicídio, investigando os fatos sociais que interferem nesse ato, que possui características que obedecem a um certo padrão (GIDDENS, 2012, p. 27).

Em se tratando das influências sociais na prática do suicídio, Durkheim adverte que

[...] se, em vez enxergá-los apenas como acontecimentos particulares, isolados uns dos outros e cada um exigindo um exame à parte, considerarmos o conjunto de suicídios cometidos numa determinada sociedade durante uma determinada unidade de tempo, constataremos que o total assim obtido não é uma simples soma de unidades independentes, uma coleção, mas que constitui por si mesmo um fato novo e sui generis, que tem sua unidade e individualidade, por conseguinte sua natureza própria, e que, além do mais, essa natureza é eminentemente social (DURKHEIM, 2000, p. 17).

À luz disso, Durkheim estabeleceu quatro tipos de suicídios: egoísta, anômico, altruísta e fatalista. Os suicídios egoístas são aqueles praticados por pessoas que estão pouco integradas na sociedade, visto que se encontram isoladas do corpo social. Já o suicídio anômico é oriundo da ausência de regulação social, como ocorre nos períodos de rápida mudança e de instabilidade social. Nesse tipo de suicídio, o indivíduo fica sem um norte para as regras e desejos (GIDDENS, 2012, p. 28).

Quanto ao suicídio altruísta, ele é marcado por pessoas que dispõem de um intenso vínculo social, uma vez que as mesmas estão fortemente integradas ao corpo social. Tal tipo de suicídio ocorre como um bem para a coletividade. Por fim, o suicídio fatalista decorre do excesso de regulação da sociedade na vida do indivíduo, que se sente impotente perante o seu destino (GIDDENS, 2012, p. 28).

Cumpre mencionar também que Durkheim buscou retratar que apesar de ocorrerem diferenças entre as taxas de suicídio de um lugar para outro, era possível observar que existiam 
padrões regulares no decorrer do tempo. Assim, Émile Durkheim enfatizou que "[...] para entender totalmente mesmo o ato aparentemente mais pessoal do suicídio, exige-se uma explicação sociológica, em vez apenas de uma explicação baseada na análise da motivação pessoal" (GIDDENS, 2012, p. 28).

No caso dos suicídios da Terceira Ponte não é possível definir qual o tipo de suicídio predominante, devido à falta de informações a respeito da motivação do ato, não sendo, também, objeto da presente pesquisa. Dessa forma, é importante, nesse trabalho, entender o conceito do ato suicida.

\section{ESTATÍSTICAS DOS SUICÍDIOS NA TERCEIRA PONTE}

Antes de analisar as estatísticas dos suicídios ocorridos na Terceira Ponte, cumpre registrar que entre os meios usados nos óbitos por lesão autoprovocada intencional (suicídio) no Espirito Santo, no de ano de 2014, a posição referente a "lugar elevado" (código x80), como a Terceira Ponte, ocupa a 4ạ (quarta) posição no ranking. Isso corresponde a 6,40\% do total de suicídios ocorridos em 2014 no ES (172 no total), ficando empatado com os óbitos por lesão autoprovocada intencional decorrente de arma de fogo (CUPERTINO, 2016).

Insta esclarecer que quando se analisa, especificamente, o número de suicídios ocorridos na Terceira Ponte, é possível aferir os seguintes dados, os quais foram disponibilizados pela Secretaria de Saúde, com base nas estatísticas divulgadas pela concessionária Rodosol, empresa que administra a referida Ponte: de 2013 a 2015, houve um total de 21 óbitos por suicídio na Terceira Ponte, todos comprovados por meio de boletim policial. Dos 21 óbitos, 18 foram identificados, sendo que 71, 43\% desses últimos, foram registrados como suicídio (CUPERTINO, 2016).

Enfatize-se que no ano de 2014 aconteceram 12 óbitos por lesão autoprovocada intencional na Terceira Ponte, correspondendo a 6,98\% em relação a todo o Estado do ES. No que se refere as tentativas, esse índice é ainda maior, correspondendo a 27,9\% (CUPERTINO, 2016). É importante registrar o aumento do número de suicídios ocorrido no ano de 2014 e as consequências de algumas reportagens no referido aumento, como se observa a seguir:

Algumas reportagens sobre o suicídio, em vez de atender ao interesse público, alimentam o interesse de um público sedento pelo espetáculo da violência. As consequências podem ser trágicas. Infelizmente, há um exemplo nefasto ocorrido recentemente no país: até 2011, havia, em média, dois suicídios por ano por precipitação de altura, a partir do vão central da Terceira Ponte, que liga os municípios de Vitória e Vila Velha, no Espírito Santo. Desde essa época, 
os casos de suicídios passaram a ser mais divulgados por jornais, televisão, rádios, portais de notícias on-line e redes sociais virtuais. Ocorreu, então, que o número de suicídios triplicou nesse ano e nos dois anos seguintes. Mas o pior estaria por vir: ao longo de 2014, foram 12 suicídios ocorridos na Terceira Ponte. Aumentou, também, o número de tentativas de suicídio (BOTEGA, 2015, p. 256).

Ao se analisar os dados entre os anos de 2005 a agosto de 2016, chega-se aos seguintes resultados de óbitos e tentativas por lesão autoprovocada intencional na Ponte Deputado Darcy Castello de Mendonça: 56 óbitos (4,67 ao ano) e 249 tentativas (20,75 ao ano) (CUPERTINO, 2016). São dados que, muito mais que provas, são informações de interesse público, tendo em vista que o suicídio se tornou um problema mundial, sendo fundamental que se atue na sua prevenção.

Quando se trata das notícias jornalísticas relatando o caso, é necessário frisar que apesar de se visualizar um aumento das matérias referentes aos suicídios que ocorrem na Terceira Ponte, ainda existe uma ausência de reportagens responsáveis sobre o assunto.

Entre as notícias que abordaram o tema com responsabilidade, pode-se citar uma carta feita pelo Conselho Regional de Psicologia (CRP-16), tendo como destinatários a empresa Rodosol (concessionária que administra a Terceira Ponte) e a Agência Reguladora de Saneamento Básico e Infraestrutura Viária do Espírito Santo (Arsi), visando a instalação de proteção na Terceira Ponte, com o intuito de diminuir os suicídios no local. Tal carta, produzida por profissionais que estudaram com profundidade a temática em análise, foi assinada também por outras entidades importantes, tais como:

- Conselho Regional de Medicina do Estado do Espírito Santo

- Conselho Regional de Serviço Social da 17a Região - Espírito Santo

- Escola Lacaniana de Psicanálise de Vitória - Espírito Santo

- Escola Brasileira de Psicanálise - Delegação Espírito Santo

- Associação Brasileira de Psiquiatria (ABP) e da Associação Psiquiátrica do Espírito Santo (APES)

No que se refere ao teor da carta aberta à Rodosol, cumpre mencionar alguns trechos que contextualizam a problemática e evidenciam a necessidade de atuar na prevenção dos repetidos casos de suicídios que ocorrem na Ponte Deputado Darcy Castello de Mendonça (Terceira Ponte):

Para além de uma manutenção puramente estrutural, acreditamos que um dos maiores desafios desta parceria reside no comprometimento da manutenção da segurança de todos que diariamente por ali transitam. A Terceira Ponte infelizmente tornou-se um dos locais escolhidos para que centenas de pessoas atentem contra suas próprias vidas. Ainda que os veículos midiáticos por motivos éticos não divulguem sobre a ocorrência de tentativas de suicídio no local, tais informações circulam livremente nas redes 
sociais incluindo vídeos, fotografias e comentários alcançando milhares de pessoas, de modo que a própria imagem deste nosso cartão postal já se encontra associada às tragédias ali ocorridas.

Pesquisas recentes sobre a psicologia do comportamento suicida têm mostrado que, além dos sentimentos de fracasso, derrota e aprisionamento vivenciados por aqueles que pensam em tirar a própria vida, um componente psicofisiológico crucial é a impulsividade. O fator impulsividade permite que pessoas em crises suicidas se engajem em tentativas de suicídio com maior agilidade quando há um método de morte facilmente acessível. A partir desses achados científicos, uma das principais recomendações da Associação Internacional para a Prevenção do Suicídio (IASP) e da Organização Mundial de Saúde (OMS) trata-se da redução de acesso aos meios de execução de suicídio.

Uma análise aprofundada dos estudos internacionais sobre a eficácia da instalação de proteções em pontes, viadutos e pontos de elevação natural na prevenção do suicídio mostra evidências de que a restrição do acesso aos meios pelos quais as pessoas tentam suicídio - especialmente pela instalação de proteções - reduz o número de mortes por suicídio não somente no local, mas também na cidade ou região em que tal local-foco se encontra. Esses estudos mostram que a instalação de proteções contra tentativas de suicídio por pulo tende a ser mais eficaz quando comparada a outros métodos de prevenção ao suicídio, uma vez que a interrupção imediata do comportamento suicida oportuniza a intervenção e a assistência.

$[\ldots]$

Acreditamos que o compromisso com a manutenção da vida seja um compromisso do poder público, da iniciativa privada e da população geral. Assim como tem sido realizado na Golden Gate Bridge e em outras pontes ao redor do mundo, a instalação de proteções pode contribuir muito para evitar que novas tentativas ou mais casos de suicídio ocorram na Terceira Ponte (CRP-16, 2016).

Vale ressaltar que a concessionária Rodosol já tem implementado algumas medidas visando diminuir o número de suicídios, como o monitoramento 24 horas por meio de câmeras; vigilância para não permitir a entrada de pedestres na Ponte; parceria com o Corpo de Bombeiros e com a Polícia Militar para uma atuação imediata nas ocorrências e a instalação de placa do CVV (BOTEGA, 2015, p. 258). Todavia, tais medidas não se mostraram suficientes, como demonstraram os dados apresentados acima.

A título de contextualização, deve-se frisar que recentemente foi apresentado à ARSP (Agência de Regulação de Serviços Públicos) um projeto que visava a instalação de barreiras de vidro ao longo da Terceira Ponte, mas o referido projeto não foi aprovado por inviabilidade técnica, optando-se por investir em um outro projeto (ESPÍRITO SANTO, 2017).

Sendo assim, diante da necessidade de medidas protetivas, deve-se analisar o caso da Rodosol, para verificar se essa empresa concessionária de serviço público possui ou não o dever 
fundamental de preservar a incolumidade dos usuários, atuando na prevenção dos repetidos casos de suicídio que ocorrem na Terceira Ponte. Isso porque ao realizar o Contrato de Concessão no. 01/98 (ESPIRÍTO SANTO, 1998) a concessionária que administra a Terceira Ponte passa a exercer as funções que antes cabiam ao Estado do Espírito Santo.

\section{TEORIA GERAL DOS DIREITOS E DEVERES FUNDAMENTAIS}

\section{DIREITOS FUNDAMENTAIS}

Os direitos fundamentais visam criar e assegurar as bases de uma vida digna, sendo definidos também, em uma visão mais normativa, como "aqueles direitos que o direito vigente qualifica como tais" (BONAVIDES, 2017, p. 575).

Pelo ponto de vista formal, os direitos fundamentais são todos os direitos e garantias designados e pormenorizados na Constituição (BONAVIDES, 2017, p. 575). Todavia, deve-se reconhecer a existência de direitos fundamentais para além da Constituição:

O direito internacional vem criando e exigindo novos direitos fundamentais que não precisam estar positivados no ordenamento interno de um país, o que significa que há, sim, direitos fundamentais fora da Constituição e que devem ser reconhecidos com esse status. De outra banda, a inexaurabilidade dos direitos fundamentais faz com que novos direitos sejam necessários e que haja, antes do reconhecimento formal de sua existência através da positivação pelo legislador constituinte, a sua afirmação pela doutrina ou jurisprudência (BEDÊ JÚNIOR, 2015, p. 36-37).

Já na perspectiva material, os direitos fundamentais variam de Constituição para Constituição, tendo cada Estado os seus próprios direitos fundamentais (BONAVIDES, 2017, p. 575). Qualquer definição de direitos fundamentais que almeja incluir por inteiro o conteúdo dos direitos fundamentais estará, no mínimo, desligada do contexto fático de cada ordem constitucional, quando analisada de forma individual. Isso acontece porque há uma valoração do conteúdo dos direitos fundamentais, conforme o contexto social e cultural concreto, não se ignorando, contudo, valores que são admitidos como universais e consensuais no que diz respeito a fundamentalidade desses direitos (SARLET; MARINONI; MITIDIERO, 2013, p. 280).

Ao tratar da invariabilidade dos direitos fundamentais, Américo Bedê Júnior (2015, p. 41) destaca que 
É preciso reconhecer que existem direitos fundamentais que superam o teste da descontextualização, ou seja, mesmo que haja uma diferente valoração de determinado direito no Brasil, na China, ou na Índia, há de se constatar a permanência de algo. Isso permite demonstrar e existência de direitos fundamentais além do texto constitucional e de uma invariabilidade desses direitos.

Nesse viés, José Afonso da Silva (2017, p. 180) afirma que a expressão direitos fundamentais dos homens, dentre as várias existentes, é a mais adequada, significando, no direito positivo, "[...] aquelas prerrogativas e instituições que ele concretiza em garantias de uma convivência digna, livre e igual de todas as pessoas". Informa o autor, ainda, que no que tange a especificação fundamentais, encontra-se a designação dos casos jurídicos sem os quais o ser humano não se realiza.

Bulos (2017, p. 523), ao definir os direitos fundamentais, registra que "[...] direitos fundamentais são o conjunto de normas, princípios, prerrogativas, deveres e institutos, inerentes à soberania popular, que garantem a convivência pacífica, digna, livre e igualitária, independente de credo, raça, origem, cor [...]".

Verifica-se, assim, que os direitos fundamentais visam assegurar uma vida digna à pessoa humana, pautada em princípios como a igualdade e a liberdade.

No presente estudo, destaca-se o direito fundamental à segurança pública, já que os suicídios que ocorrem na Terceira Ponte violam a incolumidade física dos usuários, indo de encontro ao previsto no art. 144, da CRFB/88, que estabelece o dever fundamental de todos de garantir a incolumidade das pessoas, violando, também, o direito à vida dos referidos usuários que cometem suicídio.

\section{DEVERES FUNDAMENTAIS}

Quando se aborda a temática dos deveres fundamentais, é preciso frisar que estes, apesar de estarem presentes nas Constituições, ficaram bastante tempo esquecidos, principalmente pela influência do liberalismo, que temia que tais deveres fossem utilizados em favor dos regimes autoritários. No que tange ao Brasil, a Constituição de 1988, que foi criada após um cenário de Ditadura Militar, estabeleceu muitos direitos e poucos deveres (PEDRA, 2013, p. 281-282).

José Casalta Nabais (2009, p. 15-16) informa que a temática dos deveres fundamentais é tida como das mais esquecidas da doutrina constitucional contemporânea. Segundo o autor "[...] para tal esquecimento, contribuiu decisivamente o facto de uma boa parte das actuais constituições da 
Europa Ocidental terem sido, em regra, adoptadas na sequência da queda de regimes totalitários ou autoritários [...]".

Nesse ponto, convém destacar a consideração feita por Nabais (2002, p. 12), que ao ressaltar o esquecimento dos deveres fundamentais, pontua que tais deveres foram alvo de um pacto de silêncio e de um genuíno desprezo, que fica nítido quando se compara a importância que foi dada aos direitos fundamentais se comparada com os deveres fundamentais. Nesse sentido, aduz que

[...] a linguagem politicamente correcta deste tempo, que é o nosso, não ousa falar senão de liberdade e dos direitos que a concretizam. Compreende-se assim que a outra face, a face oculta da liberdade e dos diretos, que o mesmo é dizer da responsabilidade e dos deveres e custos que a materializam, não seja bem-vinda ao discurso social e político nem à retórica jurídica (NABAIS, 2002, p. 11).

Convém lembrar que os deveres fundamentais "[...] possuem o importante papel de proteger e promover direitos fundamentais; alguns destes dependem daqueles diretamente [...] enquanto outros dependem indiretamente [...]" (PEDRA, 2013, p. 284). Sendo assim, verifica-se a importância dos deveres fundamentais para que os direitos fundamentais possam ser efetivados.

No caso da Terceira Ponte, faz-se necessário especificar quem são as pessoas que possuem o dever fundamental de assegurar a incolumidade física dos usuários, atuando na prevenção dos suicídios que ocorrem no local. Isso deve ser feito porque tal dever é essencial para promover um outro direito fundamental, qual seja, a segurança pública das pessoas que utilizam o serviço prestado pela Rodosol, já que com a prevenção evita-se que a incolumidade física dos usuários seja violada. Além disso, é preciso definir quem arcará com os custos dessa prevenção.

Cientes dessa importância dos deveres fundamentais e da necessidade de legislações e debates teóricos sobre tais deveres, já que os mesmos são tratados com menor relevância se comparados aos direitos fundamentais, o grupo de pesquisa "Estado, Democracia Constitucional e Direitos Fundamentais", da pós-graduação stricto sensu da FDV, construiu um conceito para deveres fundamentais (FABRIZ; GONÇALVES, 2013, p. 87).

Depois de muitas discussões, o grupo alcançou um conceito para o termo dever fundamental, que é "[...] uma categoria jurídico-constitucional, fundada na solidariedade, que impõe condutas proporcionais àqueles submetidos a uma determinada ordem democrática, passíveis ou não de sanção, com a finalidade de promoção de direitos fundamentais" (FABRIZ; GONÇALVES, 2013, p. 92). 
Ao utilizar a expressão "impõe condutas proporcionais", visou-se assegurar a obediência aos princípios próprios de um Estado Democrático de Direito. Além disso, quando se afirmou que a finalidade dos deveres fundamentais é promover direitos fundamentais, buscou-se estabelecer que para um dever ser considerado fundamental, ele precisa ter como razão final o fomento de um direito fundamental. Ainda no que tange ao conceito de deveres fundamentais exposto anteriormente, é preciso deixar claro que "colocar o dever fundamental como uma categoria jurídico-constitucional o leva a uma autonomia teórica relativamente aos direitos fundamentais" (FABRIZ; GONÇALVES, 2013, p.92).

Embora haja uma autonomia teórica dos deveres fundamentais, esta não exclui a relação entre os deveres e os direitos fundamentais, uma vez que

Não há direitos sem deveres, porque não há garantia jurídica ou fáctica dos direitos fundamentais sem o cumprimento dos deveres do homem e do cidadão indispensáveis à existência e funcionamento da comunidade estadual, sem a qual os direitos fundamentais não podem ser assegurados nem exercidos. E não há deveres sem direitos, porque é de todo inconcebível um estado de direito democrático assente num regime unilateral de deveres, já que contra ele se levantariam as mais elementares exigências de justiça e de respeito pelos direitos humanos [...] (NABAIS, 2009, p. 119).

Diante de tal realidade, vale lembrar que os deveres fundamentais podem estar estabelecidos na Constituição de forma explícita ou implícita. Além do mais, esses deveres podem derivar de tratados internacionais dos quais o Brasil seja signatário ou dos princípios assegurados na Constituição. Quando se analisa o aspecto material, os deveres fundamentais buscam atender às necessidades básicas da pessoa ou de toda uma coletividade, fomentando os direitos fundamentais (PEDRA, 2015, p. 1.136-1.137).

Nesse ponto, vale registrar que a segurança pública e a vida são deveres fundamentais estabelecidos na Constituição de forma explícita (art. 50, caput e 144, CRFB/88), atendendo os requisitos formais e materiais, já que estão previstos na Carta Magna e visam promover os direitos fundamentais à segurança pública e à vida.

É necessário frisar que a sanção para o desrespeito de algum dever fundamental é importante, mas não é fator determinante para a eficácia de um dever fundamental. Todavia, mesmo quando não houver uma sanção, haverá consequências jurídicas para quem descumprir tal dever (PEDRA, 2013, p. 295). 
Para entender a relação dos deveres fundamentais com o tema tratado nesse trabalho, é preciso destacar que as pessoas jurídicas, a exemplo da Rodosol, também possuem deveres fundamentais a serem cumpridos, como se pode observar no trecho a seguir:

Apesar da menção feita aos deveres humanos, ou seja, aos deveres fundamentais da pessoa humana, o desenvolvimento aqui construído também se aplica aos deveres fundamentais da pessoa jurídica, no que couber. Assim, busca-se avaliar a legitimidade da exigibilidade de deveres impostos aos particulares pela Constituição com o fim de assegurar direitos fundamentais (PEDRA, 2015, p. 1.134).

Nabais (2009, p. 109-110) esclarece que os destinatários dos deveres fundamentais não são só os indivíduos, incluindo também as pessoas coletivas, sendo que esta expressão precisa ser entendida de forma ampla, abrangendo inclusive as organizações coletivas que não possuem personalidade jurídica.

Sendo assim, ao analisar o caso da Rodosol, deve-se verificar se essa empresa concessionária de serviço público possui ou não o dever fundamental de garantir a incolumidade física dos usuários, atuando na prevenção dos suicídios que ocorrem na Terceira Ponte/ES, como uma forma de garantir o direito à segurança pública e o direito à vida dos usuários.

A partir do exposto, convém analisar outros termos importantes para o estudo em questão, quais sejam, a segurança pública, no que tange a preservação da incolumidade das pessoas, e o direito à vida.

\section{O DEVER FUNDAMENTAL DE PRESERVAR A INCOLUMIDADE DAS PESSOAS (ART. 144, CRFB/88) E O DIREITO À VIDA}

No que tange ao direito à vida, busca-se avaliar se os suicídios que ocorrem na Terceira Ponte estariam violando esse direito, que é tão caro a nossa Constituição. Afinal, a dignidade da pessoa humana é um princípio fundamental da República Federativa do Brasil. Além disso, o caput do artigo 5o, da CRFB/88, assegura que "[...] todos são iguais perante a lei, sem distinção de qualquer natureza, garantindo-se aos brasileiros e aos estrangeiros residentes no País a inviolabilidade do direito à vida [...]" (BRASIL, 1988).

Diante disso, verifica-se que o direito à vida é assegurado na nossa Constituição, sendo dever fundamental de todos preservá-lo. José Afonso da Silva (2017, p. 200) alude que a vida é a base dos 
demais bens jurídicos. Segundo esse mesmo autor, de nada valeria garantir outros direitos fundamentais, se o direito à vida não tivesse incluso nesse rol.

Uadi Lammego Bulos (2017, p.543) destaca que o direito à vida é o mais relevante dos direitos, sendo o seu conteúdo constitucional amplo, já que ele se liga a outros direitos, como à segurança e à saúde. Ao tratar da temática do suicídio, no capítulo referente ao direito à vida, afirma que

O inevitável fenômeno biológico da morte física, do qual ninguém poderá evadir-se, por mais dura que seja a jornada no invólucro carnal, não é uma facultas agendi. Independente de credo religioso ou de posição filosófica, a manifestação constituinte originária não se compactua com o ato de alguém subtrair a própria vida (BULOS, 2017, p. 551).

Outro aspecto importante é que a vida humana antecede o próprio direito, tendo este que preservá-la. Assim, a vida não pode ser considerada um direito do indivíduo sobre si mesmo, nem uma outorga jurídica-estatal. Em virtude disso, o próprio possuidor do direito à vida deve respeitála, já que ela não pertence a sua autonomia da vontade (DINIZ, 2010, p. 22).

Centrados nessa perspectiva, torna-se válido salientar o seguinte trecho

Savigny não admite, com razão, a existência de um direito sobre si próprio; isso seria legitimar o suicídio. A vida não é domínio da vontade livre. [...] 0 direito ao respeito da vida é excludendi alios, ou seja, direito de exigir um comportamento negativo dos outros (DINIZ, 2010, p.22).

À luz disso, cumpre mencionar que a vida se apresenta como o bem jurídico mais valioso do ornamento jurídico. Ela é o fundamento de todo direito individual, visto que sem vida, não existe a personalidade. Por isso é que "[...] a sua proteção jurídica interessa conjuntamente ao indivíduo e ao próprio Estado, recebendo, com acerto, assento constitucional" (BITENCOURT, 2015, p. 52).

Sobre este aspecto, vale destacar o dever do Estado de proteger o direito à vida, mesmo quando se trata de casos que envolvam práticas suicidas, visto que

Sendo um direito, e não se confundindo com uma liberdade, não se inclui no direito à vida a opção por não viver. Na medida em que os poderes públicos devem proteger esse bem, a vida há de ser preservada, apesar da vontade em contrário do seu titular. Daí que os poderes públicos devem atuar para salvar a vida do indivíduo, mesmo daquele que praticou atos orientados ao suicídio (BRANCO; MENDES, 2015, p. 260). 
Sendo assim, existe um dever fundamental de assegurar o direito à vida, uma vez atendido os requisitos formais e materiais, frisando, ainda, a importância dada pela Constituição Federal a esse bem jurídico, que é a base de todos os outros bens jurídicos.

Já em relação à segurança pública, o art. 144 da Constituição da República Federativa do Brasil de 1988 (CRFB/88) estabelece que "A segurança pública, dever do Estado, direito e responsabilidade de todos, é exercida para a preservação da ordem pública e da incolumidade das pessoas e do patrimônio [...]". Tal redação deixa evidente que a segurança pública não é dever só do Estado, mas de toda a população, que deve discutir a questão e assumi-la como responsabilidade constante (SILVA, 2017, p. 793). Além disso, a Constituição Federal assegura, em seu art. 5o, caput, a inviolabilidade do direito à segurança. Sendo assim, os repetidos casos de suicídios que acontecem na Terceira Ponte, violam não somente o direito à vida, mas também o direto à segurança dos usuários, que não têm a sua incolumidade física preservada.

O dever fundamental de preservar a incolumidade das pessoas (art. 144, da CRFB/88) será analisado no que diz respeito a atuação na prevenção dos suicídios que ocorrem na Terceira Ponte, que envolve, assim, a incolumidade física dos usuários, a qual "[...] compreende a alteração, anatômica ou funcional, interna ou externa, do corpo humano, como por exemplo, equimoses, luxações, mutilações, fraturas etc" (BITENCOURT, 2015, p. 196-196). Quando uma pessoa tenta cometer suicídio, viola-se a sua incolumidade física, podendo, em alguns casos, violar o próprio direito a vida.

Cláudio Pereira de Souza Neto (2015, p. 3.389) afirma que há duas perspectivas de segurança pública que se contrapõem desde a reabertura democrática até os dias atuais. A primeira retrata a atividade institucional da polícia, no que se refere ao seu poder bélico, de combate à criminalidade. Já a segunda, se pauta em uma prestação de serviço por parte do Estado, tendo como destinatários os próprios cidadãos. Quando a CRFB/88 tratou da segurança pública em seu art. 144, não delimitou a escolha por nenhum desses modelos em específico, mas definiu como meta das políticas de segurança a preservação da "incolumidade das pessoas e do patrimônio".

Souza Neto (2015, p. 3.390) afirma que um conceito de segurança pública adequado à nossa Constituição é

[...] um conceito que se harmonize com o princípio democrático, com os direitos fundamentais e com a dignidade da pessoa humana. Por essa razão, apenas as políticas de segurança pública alicerçadas em concepções democráticas, comprometidas com a observância efetiva desses princípios, são compatíveis com a Constituição Federal. 
Ademais, importa ressaltar que além da ordem pública, a segurança pública tutela a incolumidade das pessoas e do patrimônio, que são fundamentais, pois "[...] a segurança das pessoas e das coisas é elemento básico das condições universais, fator absolutamente indispensável para o natural desenvolvimento da personalidade humana" (PEDRA; PEDRA, 2009, p. 1.721).

Dessa forma, tem-se que a segurança pública visa assegurar o equilíbrio das relações sociais, por meio de um convívio harmonioso, requerendo a proteção dos direitos e garantias fundamentais, como o direito à vida, ao bem-estar, entre outros (PEDRA; PEDRA, 2009, p. 1.722).

Não se pode deixar de retratar o pequeno enfoque dado pela doutrina quando aborda a incolumidade das pessoas, dentro da temática da segurança pública. Embora se tenha encontrado tal obstáculo, importa, nesse momento, deixar claro que existe um dever fundamental de preservar a incolumidade das pessoas, vez que atendido o requisito formal (previsão constitucional) e material (promover o direito fundamental à segurança pública).

Visto isso, deve-se abordar outro tema importante para o presente trabalho, que é o contrato de concessão, o qual rege a relação da concessionária Rodosol com o Governo do Estado do Espírito Santo.

\section{CONTRATO DE CONCESSÃO DE SERVIÇO PÚBLICO}

O contrato firmado entre o Estado do Espírito Santo e a Rodosol é de concessão de um serviço público, que ocorre quando o Estado destina um serviço público a uma pessoa, que concorda em exercê-lo em seu nome, de acordo com que o foi posto unilateralmente pelo Poder Público. Todavia, o contrato deve assegurar o equilíbrio econômico-financeiro, em que o concessionário, em geral, obtém a remuneração da prestação do serviço, cobrando um preço dos usuários que utilizam de tal serviço (MELLO, 2010, p. 701).

A Constituição Federal trata sobre a concessão de serviços públicos em seu art. 175, afirmando que "Incumbe ao Poder Público, na forma da lei, diretamente ou sob regime de concessão ou permissão, sempre através de licitação, a prestação de serviços públicos" (BRASIL, 1988).

No âmbito infraconstitucional, a lei que trata da concessão e permissão da prestação de serviços públicos é a lei 8.987/95, que no seu art. 2o, II e III, trata das duas modalidades de concessão de serviços públicos:

II - concessão de serviço público: a delegação de sua prestação, feita pelo poder concedente, mediante licitação, na modalidade de concorrência, à 
pessoa jurídica ou consórcio de empresas que demonstre capacidade para seu desempenho, por sua conta e risco e por prazo determinado;

III - concessão de serviço público precedida da execução de obra pública: a construção, total ou parcial, conservação, reforma, ampliação ou melhoramento de quaisquer obras de interesse público, delegada pelo poder concedente, mediante licitação, na modalidade de concorrência, à pessoa jurídica ou consórcio de empresas que demonstre capacidade para a sua realização, por sua conta e risco, de forma que o investimento da concessionária seja remunerado e amortizado mediante a exploração do serviço ou da obra por prazo determinado (BRASIL, 1995);

Observa-se que as duas modalidades de concessão de serviço público precisam atender a determinados requisitos para a válida formação, que são: I) ser feitos mediante licitação; II) na modalidade de concorrência; III) delegada à pessoa jurídica ou consórcio de empresa que "demonstrem capacidade para a realização do empreendimento" (MELLO, 2010, p. 707).

A Rodosol, empresa concessionária que administra a Terceira Ponte, é regida pelo regime de concessão de serviço público precedida da execução de obra pública. Isso ocorre porque o investimento da concessionária se dá pela exploração do serviço, cobrando tarifas dos usuários que atravessam a referida Ponte.

Apesar de a lei denominar concessão de serviço público precedida da execução de obra pública, tal tipo de concessão abrange também a "conservação, reforma, ampliação ou melhoramento de quaisquer obras públicas" (Lei ํ․ 8.987/95, art. 2ㅇ, II). No que tange à conservação, não há a precedência da execução do serviço público, já que a execução é feita ao mesmo tempo da prestação do serviço, que nesse caso é o de conservação (CARVALHO FILHO, 2012, p. 370).

Nesse regime de concessão, o objeto do contrato, segundo José dos Santos Carvalho Filho (2012, p. 369-370), é analisado sob duas perspectivas, já que em um primeiro momento se firma um acordo entre as partes para que seja realizada uma obra pública e, em um segundo momento, que caracteriza a verdadeira concessão, o concedente permite que o concessionário cobre determinada tarifa dos usuários, como uma forma de explorar a obra que foi executada.

Outro ponto importante a ser analisado é que o ato administrativo de concessão necessita ser autorizado por lei, permitindo que o executivo delegue a prestação do serviço a um terceiro. Este será escolhido mediante licitação, que avaliará as propostas mais vantajosas, possibilitando a ampla concorrência (MELLO, 2010, p. 713-715).

Nos contratos de concessão, o Estado tem ampla autonomia, de acordo com o interesse da coletividade, para determinar a parte regulamentar do serviço (forma como o serviço será prestado e usufruído pelos usuários). No entanto, o Estado "[...] está peado no que concerne ao elemento 
verdadeiramente contratual da concessão, que é o equilíbrio econômico-financeiro (MELLO, 2010, p. 713).

Sobre o poder de mudança unilateral do contrato, Carvalho Filho (2012, p. 381) adverte que

Se, de um lado, esse poder constitui exercício da soberania do Estado em prol do interesse público, de outro se torna impositivo que a Administração demonstre inequivocamente a existência de fatos justificadores do exercício da prerrogativa. Sem essa contraposição, é flagrante a possibilidade de abuso de poder.

É válido mencionar que em relação a prestação de um serviço adequado ao completo atendimento dos usuários, a lei 8.987/95, que dispõe sobre o regime de concessão e permissão da prestação de serviços públicos, estabelece em seu art. $6, \S 1$, que é preciso satisfazer "as condições de regularidade, continuidade, eficiência, segurança [...]". Sendo assim, os repetidos suicídios que ocorrem na Terceira Ponte revelam que o serviço prestado pela concessionária Rodosol não está sendo adequado. Tal situação ocorre porque a segurança dos usuários não está sendo garantida, já que com frequência ocorrem mortes no local, decorrentes dos suicídios.

A partir dessa constatação, o Estado pode promover, unilateralmente, mudanças das cláusulas regulamentares, para garantir a prestação de um serviço adequado, que garanta, por exemplo, a segurança pública dos usuários, que é um direito e responsabilidade de todos (art.144, CF/88), o que inclui as pessoas jurídicas.

Tais mudanças seriam

[...] relativas à organização dele, a seu funcionamento e desfrute pelos usuários [...]. O concessionário não se pode opor às alterações exigidas, nem esquivar-se de cumpri-las ou reclamar a rescisão da concessão, desde que o objeto dela não haja sido desnaturado ou desvirtuado pelas modificações impostas. Cabe-lhe, apenas, como adiante se verá, o ressarcimento pelo desequilíbrio econômico dos termos da concessão, se este resultar da ação das novas medidas estabelecidas pelo concedente (MELLO, 2010, p. 730).

É necessário lembrar que o poder de fiscalização que recai sobre o concedente, permite ao mesmo "aplicar sanções e regulamentar o serviço; observar o cumprimento, pelo concessionário, das cláusulas contratuais referentes ao serviço; zelar pela adequada prestação do serviço e, enfim, controlar a atividade delegada" (CARVALHO FILHO, 2012, p. 393).

Todavia, o poder de fiscalização não se limita apenas ao poder concedente, já que os usuários também têm o direito de atuar na fiscalização do concessionário, de acordo com a lei no 9.074/1995. Além disso, os usuários possuem o direito de receber, periodicamente, informações 
sobre o serviço realizado por meio da concessão. Com isso, aumenta-se o controle sobre os atos do concessionário e, consequentemente, do concedente (CARVALHO FILHO, 2012, p. 398).

Nesse sentido, alude Carvalho Filho (2012, p. 399) que

É preciso haver maior conscientização do público para a defesa de seus direitos, mas de nada adiantará essa conscientização se o Poder Público concedente não demonstrar, com clareza, a efetividade de seu controle e a busca real no fim último da concessão, qual seja, a regular e eficiente prestação do serviço.

Ademais, o art. 70, II, da Lei 8.987/95 alude que são direitos e obrigações dos usuários "receber do poder concedente e da concessionária informações para a defesa de interesses individuais ou coletivos". Sendo assim, a Rodosol tem o dever de prestar informações sobre os suicídios que ocorrem na Terceira Ponte, já que o direito à vida e à segurança pública são de interesse de toda a coletividade, por se tratarem de direitos difusos.

A partir do exposto, observa-se, claramente, que o Estado possui o dever fundamental de garantir o direito à vida e à segurança pública dos cidadãos, no que tange à preservação da incolumidade das pessoas. O que se busca discutir aqui é se uma empresa concessionária, no caso em questão a Rodosol, também teria o dever fundamental de preservar a incolumidade dos usuários da Terceira Ponte, atuando na prevenção dos suicídios, como uma forma de garantir tais direitos, visto que os mesmos recebem um tratamento especial da nossa Constituição. Tal debate torna-se ainda mais necessário quando uma empresa, por meio de um contrato de concessão, assume a administração que caberia ao Estado, o qual possui os deveres fundamentais de assegurar o direito à vida é a segurança pública dos indivíduos.

Mais do que isso, é preciso também definir quem arcará com os custos das medidas adotadas para a prevenção dos suicídios que ocorrem na Terceira Ponte.

\section{ATUAÇÃO NA PREVENÇÃO DOS SUICÍDIOS NA TERCEIRA PONTE E OS CUSTOS DOS DIREITOS}

Quando se analisou o dever fundamental de garantir a incolumidade das pessoas (art. 144, CRFB/88), verificou-se que todos possuem tal dever, tendo em vista que a segurança pública é responsabilidade de todos. Dessa forma, a empresa concessionária que administra a Terceira Ponte também possui o dever fundamental de garantir a incolumidade dos usuários, por meio de medidas específicas, que deverão ser implementadas com base em estudos técnicos, que permitam definir a melhor forma de atuar na prevenção dos suicídios que acontecem na Terceira Ponte. 
Assim, a concessionária Rodosol torna-se responsável pela execução do projeto que implementará as medidas preventivas, tendo em vista que ela é a empresa que, por meio de um contrato de concessão, assumiu a administração da Terceira Ponte e as responsabilidades que antes eram do Estado do Espírito Santo.

É preciso lembrar que não basta importar técnicas adotadas por outros países, no que se refere às medidas de prevenção dos suicídios, sem antes analisar as peculiaridades do caso concreto (Terceira Ponte). As medidas adotadas em outros países podem servir de parâmetro para buscar a técnica mais eficaz de assegurar a incolumidade e a vida dos usuários da Terceira Ponte (art. 144, da CRFB/88).

Após definir que a Rodosol possui o dever fundamental de garantir a incolumidade e a vida dos usuários, podendo exigir da referida empresa medidas específicas de prevenção dos suicídios que ocorrem na Ponte Deputado Darcy Castelo de Mendonça, cabe realizar uma nova indagação: quem arcará com os custos de tais medidas?

A partir dessa indagação, é mister tratar da face oculta dos Direitos Fundamentais, que são os deveres e os custos dos direitos. Nesse momento, é oportuno destacar os custos dos direitos, para que se possa, ao final, definir quem arcará com os custos das medidas específicas adotadas para a prevenção dos suicídios que ocorrem na Terceira Ponte.

José Casalta Nabais (2002, p. 19) afirma que no Estado de Direito Democrático há três tipos de custos lato sensu. O primeiro são os custos relacionados à existência e sobrevivência do estado, como o dever de defesa da pátria; o segundo se refere ao funcionamento democrático do estado, a exemplo dos deveres de votar; o terceiro diz respeito aos custos em sentido estrito, materializado, por exemplo, no dever de pagar impostos.

Ao analisar, especificamente, os custos dos direitos fundamentais em sentido estrito, não frisando nos custos pessoais, Nabais (2002, p. 20) estabelece que todos os direitos possuem custos financeiros públicos. Nesse viés, leciona que

Têm portanto custos públicos não só os modernos direitos sociais, aos quais toda a gente facilmente aponta esses custos, mas também custos públicos os clássicos direitos e liberdades, em relação aos quais, por via de regra, tais custos tendem a ficar na sombra ou mesmo no esquecimento (NABAIS,2002, p. 20).

Vale registrar que os custos dos direitos sociais se materializam em despesas públicas, refletindo no universo dos seus titulares, ao passo que os custos dos clássicos direitos e liberdades se consumam nos gastos com a sua promoção e efetivação. Dessa forma, "[...] todos os direitos têm 
custos financeiros públicos, sejam custos indirectos nos clássicos direitos e liberdades, sejam custos directos nos direitos sociais" (NABAIS, 2002, p. 21).

Nesse viés, ao analisar os responsáveis por arcar com os custos das medidas específicas de atuação na prevenção dos suicídios que ocorrem na Terceira Ponte, como uma forma de garantir o direito fundamental à segurança pública (art. 144, da CRFB/88) e o direito à vida (art. 5, da CRFB/88) dos usuários, tem-se três alternativas: o custo das medidas protetivas poderá ser arcado pela própria Rodosol (que, sem retenção no fluxo de veículos, terá um incremento de receita), pelos usuários (mediante o aumento no valor ou na duração do pedágio), ou pela sociedade (através da receita pública, ou seja, por meio dos impostos pagos por toda a sociedade).

Diante da necessidade e adequação da instalação de medidas de proteção ao longo da Terceira Ponte pela Rodosol, deve-se pensar no equilíbrio econômico-financeiro do contrato de concessão a partir da responsabilidade de todos para com a incolumidade das pessoas.

Assim, com equidade, entendemos que os custos das medidas preventivas adotadas na Terceira Ponte, por parte da concessionária Rodosol, que também possui o dever fundamental de preservar a incolumidade das pessoas, deverá ser custeado por toda a sociedade, por meio da receita pública, oriunda dos impostos pagos por toda a sociedade. Isso ocorre porque o art. 144, da CRFB/88, ao tratar do dever fundamental de preservar a incolumidade das pessoas, é claro ao afirmar que a segurança pública é responsabilidade de todos, assegurando, ao mesmo tempo, a inviolabilidade do direito à vida (art. 5, caput, da CRFB/88).

O fato da concessionária Rodosol também ser responsável por preservar a incolumidade das pessoas, não atribui a ela o dever de arcar sozinha com os gastos das medidas preventivas implementadas. Exigir que a concessionária arque com todos os custos das medidas preventivas adotadas para prevenir os suicídios que são cometidos na Terceira Ponte, significa colocar sob a empresa um ônus excessivo, o que seria desproporcional.

Nesse sentido, Adriano Sant'Ana Pedra (2015, p. 1.138-1.139) destaca que

[...] o dever imposto a alguém não deve corresponder a um esforço exorbitante para essa pessoa. Mesmo em decorrência da ideia de solidariedade não se pode impor ao sujeito do dever um sacrifício extraordinário - ou desproporcional - com o fim de salvaguardar determinado direito. Somente será possível exigir do sujeito do dever um "sacrifício trivial". $[\ldots]$

É necessário haver equidade na onerosidade assumida por cada pessoa. Sobretudo naquelas situações em que o ônus incide especificadamente em alguns poucos indivíduos, e tem a coletividade como sua beneficiária, o ordenamento jurídico deve prever, tanto quanto possível, a redistribuição dessa onerosidade para com os demais membros da sociedade. 
Por isso, com equidade e baseado no art. 144, da CRFB/88, o custo das medidas preventivas deverá ser redistribuído para toda a sociedade, por meio da receita pública, tendo em vista a responsabilidade de todos para com a incolumidade das pessoas e a garantia do equilíbrio econômico-financeiro do contrato de concessão no 01/98, firmando entre a Rodosol e o Estado do Espírito Santo. Dessa forma, não será exigido da concessionária um sacrifício exorbitante, distribuindo a onerosidade oriunda da implementação das medidas de prevenção dos suicídios na Terceira Ponte.

\section{CONCLUSÃO}

A partir do estudo realizado, chegou-se à conclusão de que existe um dever fundamental de preservar a incolumidade das pessoas (art. 144, da CRFB/88) e de assegurar o direito à vida, preenchendo, assim, os requisitos formais e materiais, uma vez que tais deveres fundamentais estão previstos na Carta Magna e visam promover outros direitos fundamentais (direito à segurança pública e direito à vida).

Além disso, concluiu-se que a concessionária Rodosol, uma pessoa jurídica, também possui o dever fundamental de preservar a incolumidade das pessoas, atuando na prevenção dos suicídios que ocorrem na Terceira Ponte, tendo como base dois direitos previstos na Constituição Federal de 1988, quais sejam: o direito à vida e à segurança pública.

O primeiro está previsto no art. 50, caput, da CRFB/88, sendo considerado um direto inviolável, que deve ser assegurado por todos, o que inclui as pessoas jurídicas, que também podem ser portadoras de deveres fundamentais. Nesse viés, vale destacar que o direito à vida, que está diretamente relacionado com o princípio da dignidade da pessoa humana, dispõe de um importante prestígio constitucional, afinal, ele é, segundo Bitencourt (2015, p. 52), o fundamento dos demais direitos, como os da personalidade. Dessa forma, é essencial que tal direito seja preservado, principalmente nos locais em que ocorrem repetidos suicídios, uma vez que o direito à vida está sendo violado.

O segundo também está disposto no art. 5o, caput, da CRFB/88, além do art. 144, do mesmo diploma, que assegura que o direito à segurança pública é responsabilidade de todos, o que deixa 
claro que o dever fundamental de garantir a segurança pública também se aplica à Rodosol, que deve atuar na prevenção dos suicídios, como uma forma de garantir a incolumidade física dos usuários da Terceira Ponte. É importante lembrar que no caso da Rodosol, a própria lei que regula os contratos de concessão (Lei 8.987/95) exige que para a prestação de um serviço adequado é necessário atender ao requisito da segurança dos usuários.

Verificou-se, ainda, que o dever fundamental de preservar a incolumidade das pessoas (art. 144, da CRFB/88) é de responsabilidade de todos, inclusive da concessionária Rodosol. Embora a concessionária também seja responsável por preservar a incolumidade dos usuários, isso não significa que ela deva arcar sozinha com os custos das medidas adotadas para prevenir os suicídios que são cometidos na Terceira Ponte.

Isso acontece porque o ônus que recai sobre a concessionária Rodosol não pode ser excessivo, sendo necessário, assim, que a onerosidade decorrente de tais medidas preventivas seja redistribuída com os demais membros da sociedade, já que o art. 144, da CRFB/88, ao tratar do dever fundamental de preservar a incolumidade das pessoas, deixa claro que a segurança pública é responsabilidade de todos.

Assim, com equidade, concluiu-se que os custos oriundos das medidas específicas adotadas para prevenir os suicídios que ocorrem na Terceira Ponte deverá ser arcado por toda a sociedade, por meio da receita pública, ou seja, por meio dos impostos pagos por toda a sociedade, assegurando o equilíbrio econômico-financeiro do contrato de concessão firmado entre a Rodosol e o Estado do Espírito Santo.

\section{REFERÊNCIAS}

BEDÊ JÚNIOR, Américo. A retórica do direito fundamental à privacidade: a validade da prova obtida mediante filmagens nos ambientes públicos e privados. Salvador: Juspodivm, 2015.

BITENCOURT, Cezar Roberto. Tratado de direito penal: parte especial 2, dos crimes contra a pessoa. 15. ed. São Paulo: Saraiva, 2015.

BONAVIDES, Paulo. Curso de Direito Constitucional. 32. ed. São Paulo: Malheiros, 2017.

BOTEGA, Neury José. Crise suicida: avaliação e manejo. Porto Alegre: Artmed, 2015.

BRANCO, Paulo Gustavo Gonet; MENDES, Gilmar Ferreira. Curso de Direito Constitucional. 10. ed. São Paulo: Saraiva, 2015.

BRASIL. Constituição [da] República Federativa do Brasil de 1988. Disponível em: < http://www.planalto.gov.br/ccivil_03/constituicao/constituicaocompilado.htm>. Acesso em: 16 ago. 2017. 
. Lei no. 8.987, de 13 de fevereiro de 1995. Dispõe sobre o regime de concessão e permissão da prestação de serviços públicos previsto no art. 175 da Constituição Federal, e dá outras providências. Diário Oficial da República Federativa do Brasil, Brasília, DF, 14 de fevereiro de 1995, p. 1917. Disponível em: < http://www.planalto.gov.br/ccivil_03/leis/L8987cons.htm>. Acesso em: 16 maio 2017.

. Lei 9.074, de 07 de julho de 1995. Estabelece normas para outorga e prorrogações das concessões e permissões de serviços públicos e dá outras providências. Diário Oficial da República Federativa do Brasil, Brasília, DF, 08 de julho de 1995, p. 10125. Disponível em: http://www.planalto.gov.br/ccivil_03/leis/L9074compilada.htm. Acesso em: 16 out. 2017.

- Ministério da Saúde. Setembro Amarelo: Ministério da Saúde lança agenda estratégica de prevenção ao suicídio. Setembro de 2017. Disponível em: < http://portalarquivos.saude.gov.br/images/pdf/2017/setembro/21/Coletiva-suicidio-21-09.pdf>. Acesso em: 13 out. 2017.

BULOS, Uadi Lammêgo. Curso de direito constitucional. 10.ed. São Paulo: Saraiva, 2017.

CARVALHO FILHO, José dos Santos. Manual de Direito Administrativo. 25. ed. São Paulo: Editora Atlas S.A, 2012.

CONSELHO REGIONAL DE PSICOLOGIA DA 16 REGIÃO (CRP-16). Carta Aberta à Rodosol e à ARSP solicitando a instalação de redes de proteção na Terceira Ponte. Vitória/ES, 02 de Setembro de 2016. Disponível em: <http://crp16.org.br/carta-aberta-a-rodosol-e-a-agencia-reguladora-desaneamento-basico-e-infraestrutura-viaria-do-espirito-santo-arsi/>. Acesso em: 15 out. 2017.

CUPERTINO, Edileusa. Secretária de Estado da Saúde do Espírito Santo. Suicídios no Espírito Santo: notificar também é cuidar. Disponível em: <http://www.sauesp.org.br/sps004/sps004-edleusagomes-ferreira-cupertino.pdf>. Acesso em: 27 out. 2016.

DURKHEIM, Émile. O Suicídio: estudo de sociologia; tradução Mônica Stahel - São Paulo: Martins Fontes, 2000.

DINIZ, Maria Helena. O estado atual do biodireito. 7. ed. São Paulo: Saraiva, 2010.

ESPIRÍTO SANTO. ARSP define nova tecnologia a ser instalada para segurança da Terceira Ponte. Vitória, 11 de outubro de 2017. Disponível em: <https://www.es.gov.br/Noticia/arsp-define-novatecnologia-a-ser-instalada-para-seguranca-da-terceira-ponte>. Acesso em: 28 out. 2017.

. Contrato de concessão n. 01/98. Dispõe sobre o contrato de concessão no. 01/98, referente ao processo DER/ES no 01/98 - edital de concorrência pública no. 01/98. Governo do Estado, Secretária dos Transportes e Obras Públicas. Disponível em: http://www.arsi.es.gov.br/download/contrato01_98.pdf>. Acesso em: 02 maio 2017.

Projeto de lei no. 035/2014, de 12 de fevereiro de 2014. Dispõe sobre a obrigação da instalação de grades ou telas de contenção/proteção em toda extensão da ponte deputado Darcy Castello de Mendonça (3a ponte). Poder Legislativo, Espírito Santo. Disponível em: <http://www.al.es.gov.br/novo_portal/> . Acesso em: 15 out. 2017. 
FABRIZ, Daury Cesar; GONÇALVES, Luísa Cortat Simonetti. Dever Fundamental: a construção de um conceito. In. DE MARCO, Christian Magnus et al. Direitos Fundamentais Civis: teoria geral e mecanismos de efetividade no Brasil e na Espanha. Tomol. Joaçaba: Editora UNOESC, 2013. p. 8796.

GIDDENS, Anthony. Sociologia. 6. ed. Porto Alegre: Penso, 2012.

MACENTE, Luciene Bolzam; ZANDONADE, Eliana. Estudo da série histórica de mortalidade por suicídio no Espírito Santo (de 1980 a 2006). Jornal Brasileiro de Psiquiatria, 2011. Disponível em: <http://www.scielo.br/pdf/jbpsiq/v60n3/01.pdf>. Acesso em: 27 set. 2015.

MELLO, Celso Antônio Bandeira de. Curso de Direito Administrativo. 27. ed. São Paulo: Malheiros Editores, 2010.

NABAIS, José Calsata. O dever fundamental de pagar impostos: contributo para a compreensão constitucional do estado fiscal contemporâneo. Coimbra: Almedina, 2009.

A face oculta dos direitos fundamentais: os deveres e os custos dos direitos. Revista Direito Mackezine, ano 3, número 2, p. 9-30, 2002. Disponível em: http://editorarevistas.mackenzie.br/index.php/rmd/article/view/7246/4913. Acesso em: 03 set. 2017.

OMS. Organização Mundial de Saúde. Prevenção do Suicídio: um recurso para conselheiros. Genebra, 2006. Disponível em: < http://www.who.int/mental_health/media/counsellors_portuguese.pdf>. Acesso em: 25 set. 2015.

PEDRA, Adriano Sant'Ana. A importância dos deveres humanos na efetivação de direitos. In: ALEXY, Robert et al (orgs.). Níveis de Efetivação dos Direitos Fundamentais Civis e Sociais: um diálogo Brasil e Alemanha. Joaçaba: Editora Unoesc, 2013, p. 281-304.

A solidariedade e deveres fundamentais da pessoa humana. In: GALUPPO et al. Human Rights, Rule of Law and the Contemporary Social Challenges in Complex Societies: proceedings of the XXVI World Congresso f Philosophy of Law and Social Philosophy of the Internationale Vereinigunf fur Rechts - und Sozialphilosophie. Belo Horizonte:Initia Via, 2015, p. 1.133-1.148.

; PEDRA, Anderson Sant'ana. Capítulo III: da segurança pública. In: BONAVIDES, Paulo; MIRANDA, Jorge; AGRA, Walber de Moura (Coords.). Comentários à Constituição Federal do Brasil. Rio de Janeiro: Forense, 2009. p. 1.719-1.743.

SARLET, Ingo Wolfgang; MARINONI, Luiz Guilherme; MITIDIERO, Daniel. Curso de direito constitucional. 2.ed. São Paulo: editora revista dos tribunais, 2013.

SILVA, José Afonso da. Curso de Direito Constitucional Positivo. 40. ed. São Paulo: Malheiros, 2017.

SOUZA NETO, Cláudio Pereira de. Capítulo III: da segurança pública. In: CANOTILHO, J. J. Gomes; MENDES, Gilmar F.; SARLET, Ingo W.; STRECK, Lenio L. (Coords.). Comentários à Constituição do Brasil. São Paulo: Saraiva/Almedina, 2013. p. 3.389-3.390. 
VAREJÃO, Victoria. Ministério Público do ES pede relatório de suicídios na 3a Ponte. G1 ES, Espirito Santo, 11 jun. 2014. Disponível em: < http://g1.globo.com/espiritosanto/noticia/2014/06/ministerio-publico-do-es-pede-relatorio-de-suicidios-na-3-ponte.html >. Acesso em: 27 set. 2015.

YIN, Robert K. Estudo de Caso: planejamento e métodos. 2.ed. Porto Alegre: Bookman, 2001.

Trabalho enviado em 12 de julho de 2018

Aceito em 11 de janeiro de 2019 